\title{
PERLINDUNGAN HUKUM BAGI KONSUMEN E-COMMERCE MENURUT UNDANG - UNDANG NO.8 TAHUN 1999 TENTANG PERLINDUNGAN KONSUMEN
}

\author{
Oleh: \\ Ria Sintha Devi ${ }^{1)}$ \\ Feryanti Simarsoit ${ }^{2)}$ \\ Universitas Darma Agung, Medan ${ }^{1,2)}$ \\ E-mail: \\ $\frac{\text { kokriasintha@gmail.com }}{\text { feryantishtg@gmail.com }}^{2)}$
}

\begin{abstract}
Trading activities in the community have developed very rapidly. This is influenced by the development of trade using internet-based technology known as Electronic Transactions (ecommerce). E-commerce can be interpreted as trading on the internet. For this reason, this research will find out about the arrangements regarding consumer protection in Indonesia, the implementation of consumer protection in electronic transactions at PT.Solusi Ecommerce Global and about the resolution of consumer disputes on electronic transactions at PT. Global E-commerce solutions. The study was conducted using a combination of normative legal research and sociological legal research. Sources and types of data used are primary data and secondary data. Data collection techniques use literature studies and also through direct interviews with relevant companies. The conclusion that can be drawn in this study is that based on Law No.8 of 1999 concerning Consumer Protection has provided guarantees and protection of consumer rights in Indonesia. PT.Solusi E-commerce Global as a business actor has contractual and statutory responsibilities towards consumers or clients and also guarantees the fulfillment of consumer rights as agreed in the contracts they have previously agreed upon and also as contained in the UUPK. So far, PT. Global E-commerce Solution has never faced a consumer dispute, and if there are only complaints from consumers, then it will be settled amicably by both parties at that time.
\end{abstract}

Keywords: Consumer Protection, E-commerce

\begin{abstract}
ABSTRAK
Kegiatan perdagangan di masyarakat telah berkembang sangat pesat.Hal tersebut dipengaruhi salah satunya dengan berkembangnya perdagangan yang mempergunakan teknologi yang berbasis internet yang dikenal dengan istilah Transaksi Elektronik (e-commerce).Ecommerce dapat diartikan sebagai perdagangan di internet. Untuk itu penelitian ini akan mencari tahu tentang pengaturan mengenai perlindungan konsumen di indonesia, pelaksanaan perlindungan konsumen pada Transaksi elektronik di PT.Solusi e-commerce global dan mengenai penyelesaian sengketa konsumen pada Transaksi elektronik di PT.Solusi Ecommerce Global. Penelitian dilakukan dengan menggunakan metode gabungan antara penelitian hukum normatif dan penelitian hukum sosiologis. Sumber dan jenis data yang dingunakan adalah data primer dan data sekunder.Teknik pengumpulan data menggunakan studi kepustakaan dan juga melalui wawancara langsung kepada perusahaan yang terkait. Kesimpulan yang dapat ditarik dalam penelitian ini adalah bahwa berdasarkan Undang-
\end{abstract}


Undang No.8 tahun 1999 Tentang Perlindungan Konsumen telah memberikan jaminan dan perlindungan atas hak-hak konsumen di Indonesia. Penyelenggara Transaksi Elektronik PT. Solusi E-commerce Global sebagai pelaku usaha memiliki tanggung jawab kontraktual dan tanggung jawab perundang-undang terhadap konsumen atau client-nya dan juga menjamin terpenuhi hak-hak konsumen sebagaima tedapat dalam kontrak yang mereka sepakai sebelumya dan juga sebagaimana terdapat dalam UUPK. Sejauh ini PT. Solusi E-commerce Global belum pernah menghadapi sengketa konsumen, dan jikalau ada hanyalah komplainkomplain dari konsumen, maka diselesaian secara damai oleh kedua belah pihak saat itu juga.

\section{Kata Kunci: Perlindungan Konsumen, E-commerce}

\section{PENDAHULUAN}

Salah satu hasil perkembangan ilmu pengetahuan dan teknologi antara lain adalah teknologi dunia maya yang dikenal dengan istilah internet. Melalui internet seseorang dapat melakukan berbagai macam kegiatan, tidak hanya terbatas pada lingkup lokal atau nasional. tetapi juga secara global bahkan internasional, sehingga kegiatan yang dilakukan melalui internet ini merupakan kegiatan yang tanpa batas. artinya seseorang dapat berhubungan dengan siapapun yang berada dimanapun dan kapanpun. Jika dilihat dari seluruh aspek kehidupan manusia yang terkena dampak kehadiran internet adalah sektor bisnis atau perdaganngan. sektor bisnis dan perdagangan merupakan sektor yang paling cepat tumbuh, Kegiatan bisnis perdagangan melalui internet yang dikenal dengan istilah electronic commerce yang disebut juga dengan e-commerce. $E$ commerce merupakan hasil dari kemajuan ilu pengetahuan dan teknologi, pada umumnya e-commerce merujuk pada semua bentuk transaksi komersial yang menyangkut organisasi dan individu yang didasarkan pada pemrosesan dan transmisi data yang digitalisasika, termasuk teks, suara, dan gambar.

Bukti nyata dari perkembangan ilmu pengetahuan dan teknologi tersebut, kini hadir salah satu situs belanja ecommerce terbesar di Indonesia yaitu PT.Solusi E-commerce Global (Mataharimall.com). Dimana PT.Solusi Ecommerce Global (Mataharimall.com), adalah situs belanja terbesar yang menyediakan lebih dari ratusan produk dengan harga terbaik dari segala kebutuhan mulai dari fashion wanita, fashion pria, kesehatan, kecantikan, handphone, tablet, laptop, lifestyle, hobi dan keperluan lainya

PT.Solusi E-commerce Global merupakan anak perusahan dari Lippo Group yang diluncurkan resmi pada tanggal 9 September 2015 oleh Bapak Hadi Wenas sebagai CEO, Bapak Adrian Suherman sebagai Co-CEO aCommerce, Bapak Arnold Sebastian sebagai Chief Tecnology Officer dan Adrian Suherman sebagai komisaris di PT.Solusi E-Commerce Global (Mataharimall.com).

Berdasarkan penelitian yang dilakukan pada perusahaan e-commerce yang bernama Mataharimall.com pada PT.Solusi E-commerce Global, ditemukan bentuk permasalahan yang terjadi kepada konsumen. Dimana bentuk permasalahan tersebut yakni banyak kecacatan pada barang yang tidak sesuai dengan spesifikasi gambar yang ditawarkan melalui media eletronik dan lambatnya pengiriman barang yag tidak sesuai dengan perjanjian, dengan adanya fenomena yang demikian ini, yakni semakin majunya ilmu pengetahuan dan teknologi yang merupakan motor penggerak bagi produktivitas dan efesiensi produsen atas barang atau jasa yang dihasilkan dalam rangka mencapai kegiatan sasaran usaha, maka perlindungan hukum terhadap konsumen dipandang sangat penting keberadaanya dan sangat berpengaruh sedimikian rupa. Sebab dalam rangka mengejar produktifitas dan efesiensi tersebut, pada akhirnya baik secara langsung atau maupun tidak langsung konsumenlah yang menanggung dampaknya.

Lahirnya Undang-undang Nomor 8 tahun 1999 tentang Perlindungan Konsumen pada tanggal 20 April 1999 dan 
diundangkan melalui lembaran Negara Republik Indonesia 1999 nomor 42, dan sesuai dengan ketentuan penutup pada pasal 65 dinyatakan bahwa undang undang Perlindungan Konsumen berlaku satu tahun sejak diundangkan, maka diharapkan upaya perlindungan terhadap konsumen di Indonesia yang selama ini terabaikan dapat menjadi lebih diperhatikan.

Berdasarkan uraian di atas sangatlah penting perlindungan hukum terhadap konsumen dalam E-commerce, maka penulis memilih dan uraikan dalam sebuah penulisan hukum yang berjudul "PERLINDUNGAN HUKUM BAGI KONSUMEN E-COMMERCE MENURUT UNDANG - UNDANG NO.8 TAHUN 1999 TENTANG PERLINDUNGAN KONSUMEN.

\section{TINJAUAN PUSTAKA}

Menurut Pasal 1 angka 2 Undang Undang No.8 Tahun 1999 Tentang Perlindungan Konsumen adalah setiap orang pemakai barang dan jasa yang tersedia dalam masyarakat baik bagi kepentingan sendiri, keluarga, orang lain, maupun mahluk lain dan tidak untuk diperdagangkan. $E-$ Commerce merupakan suatu istilah yang sering digunakan atau didengar saat ini yang berhubungan dengan internet, e-commerce merupakan pembeli dan penjual serta pemasaranya melalui media eltronik. $E$ commerce juga adalah transaksi bisnis yang melalui media internet yang dilakukan secara sambungan internet dan memiliki cara bayar dari barang - barang yang di beli.

E-commerce selaku pelaku usaha, dalam melaksanakan kegiatan usaha sebagaimana diatas perlu memerhatikan hak-hak dan kewajibanya sebagaimana yang diatur dalam pasal 6 dan pasal 7 Undang - Undang No.8 tahun 1999 tentang Perlindungan Konsumen juga hak dari konsumenya sendiri atau lebih sering disebut dengan "costumer" guna terjalinya hubungan ekonomi yang baik dan terciptanya kepastian hukum diantara kebelah pihak. Jadi dalam hal ini hukum perlindungan konsumen menjadi aturan dalam hubungan hukum kedua belah pihak yang bukan saja melindungi kepentingan dari konsumen juga melindungi kepentingan pelaku usaha.

Surat Keputusan Nomor: 350/MPP/Kep/12/2001 tanggal 10 Desember 2001 tentang Tugas dan Wewenang Badan Penyelesaian Sengketa Konsumen Pasal 1 angka 8, dimana yang dimaksud dengan sengketa konsumen adalah sengketa antar pelaku usaha dengan konsumen yang menuntut ganti kerugian atas kerusakan, pencemaran dan/atau menderita kerugian akibat mengomsumsi barang dan/ atau memanfaatkan jasa. Kerugian yang dimaksud bisa terjadi akibat kelalaian pelaku usaha dan faktor alam.

\section{METODE PELAKSANAAN}

Jenis metode yang digunakan dalam penelitian ini adalah gabungan antara penelitian hukum normatif dan penelitian hukum sosiologis. Jenis data yang digunakan adalah data primer dan data sekunder. Sumber data primer diproleh dari hasil wawancara dari nara sumber yang belokasi di wilayah hukum kota Medan. Dipilihnya kota Medan karena banyaknya pembeli yang melakukan transaksi elektronik (e-commerce)dan penjual barang memasarkan produknya secara online, dan banyak pula ditemukan permasalahan wanprestasi dari jual beli tersebut. Sementara Data sekunder dalam penelitian ini meliputi : Bahan hukum primer yaitu Kitab Undang - undang No. 8 Tahun 1999 tentang Perlindungan Konsumen. Bahan hukum sekunder, yaitu seperti buku - buku, majalah, Koran, bahkan dari dokumen pribadi atau pendapat dari kalangan pakar hukum yang relevan dengan objek telaahan penelitian ini, Bahan hukum tersier, yaitu kamus umum, kamus hukum, yang menjadi tambahan bahan bagi penulisan penelitian ini sepanjang memuat informasi yang relevan dengan penelitian ini.

\section{HASIL DAN PEMBAHASAN \\ Perlindungan Hukum Pada Transaksi Elektronik (E-Commerce) Di PT. Solusi E- Commerce Global (Mataharimall.Com)}


PT.Solusi E-commerce Global merupakan anak perusahaan dari Lippo Group, Lippo Group adalah perushaan besar yang berdiri semenjak tahun 1950 oleh Bapak Mocthar Riady. PT.Solusi Ecommerce Global pertama kali diumumkan kehadiranya oleh Lippo Group pada tanggal 25 Febuari 2015, dan pada tanggal 9 September 2015 resmi diluncurkan oleh Bapak Hadi Wenas sebagai CEO, Bapak Adrrian Suherman sebagai Co-CEO Commerce, Bapak Arnold Sebastian sebagai Chief Tecnology Officer.PT.Solusi Ecommerce Global sebagai perusahaan ecommerce yang telah mendapatkan pengesahaan dari Mentri Hukum dan Hak Azasi Manusia, dengan nomor AHU.5981.01.01 yang beralamat Jl.R.Rasuna Said Kav B-12,Karet Kuningan,Setiabudi, Jakarta Indonesia. PT.Solusi E-commerce Global salah satu perusahaan e-commerce $\mathrm{di}$ Asia Tenggara yang mengadopsi sistem 020 (Online To Offline \& Offline to Online) yang memungkinkan para pelangganya untuk membayar, mengambil atau mengembalikan produk di ratusan cabang kioskMataharimall.com.

PT.Solusi E-commerce Global dengan situs www.mataharimall.com merupakan situs belanja terbesar yang menyediakan lebih dari ratusan produk dengan harga terbaik dari segala kebutuhan mulai dari fashion wanita, fashion pria, kesehatan, kecantikan, handphone, tablet, laptop, lifestyle, hobi dan keperluan lainya.

PT.Solusi E-commerce Global sebagai perusahaan e-commerce terbesar di Indonesia melakukan kegiatan usaha dengan sistem Transaksi Elektronik atau $E$ commerce. Adapun kegiatan-kegiatan usaha yang dilakukan PT.Solusi E-commerce sebagai berikut :

1. Penjualan Fashion.

2. Penjualan alat Kesehatan, Kecantikan.

3. Penjualan benda-benda Elektronik.

4. Penjualan kebutuhan Gaya Hidup (Lifestyle).

5. Penjualan Pulsa.

6. Penjualan Ticket nonton.

7. Penjulan Voucher-voucher promo.
Penjualan Fashion yang dilakukan oleh PT.Solusi E-commerce Global meliputi fashion pria, wanita dan anak-anak.

Adapun yang menjadi hak konsumen yang diberikan oleh PT.Solusi E-commerce Global yang melakukan Transaksi Elektronik pada umumnya mendapatkan fasilitas dan pelayanan :

1. Pemberitahuan

Setiap pemberitahuan kepada pelanggan sehubungan dengan kontrak tertulis baik melalui surat atau email kepada pihak yang bersangkutan di alamat e-mail terakhir yang diketahui.

a. Pemberitahuan yang disampaikan melalui pos harus dianggap telah diterima oleh yang bersangkutan dalam dua hari sejak tanggal pengiriman, jika pengiriman ditunjukan ke alamat penerima di Indonesia.

b. Pemberitahuan yang disampaikan melalui e-mail dinggap telah diterima oleh yang bersangkutan dalam dua hari kalender sejak tanggal email dikirim.

2. Perlindungan Data Pribadi.

Pada PT.Solusi E-commerce Global konsumen juga memproleh hak sebagimana yang terdapat pada Pasal 4 Undang-Undang Perlindungan Konsumen, sebagai berikut :

1. Hak atas kenyamanan, keamanan, dan keselamatan dalam mengkonsumsi jasa, dalam hal ini perusahan menyediakan coustmer care untuk konsumen menanyakan pemesanan atau melakukan transaksi elektronik.

2. Hak atas informasi yan benar, jelas, dan jujur mengenai kondisi dan jaminan jasa, artinya PT.Solusi E-commerce Global memberikan informasi yang jelas kepada konsumenya termasuk menanggapi segala pertanyaan konsumennya.

3. Hak untuk didengar pendapat dan keluhannya atas jasa yang digunakan, jika konsumen memiliki keluhan maka PT.Solusi E-commerce Global akan menanggapi keluhan tersebut, dan berusaha memberikan solusi terbaik

4. Hak untuk mendapat pembinaan dan pedidikan konsumen,biasanya pada melakukan transaksi elektronik, konsumen mendapatkan langkah- 
langkah dan ketentuan yang diberikan PT.Solusi E-commerce Global.

5. Hak untuk diperlakukan atau dilayani secara benar dan jujur serta tidak diskriminatif, PT. Solusi E-commerce Global senantiasa memberikan pelayanan yang benar dan jujur pada konsumennya.

Dan yang menjadi kewajiban dari konsumen PT.Solusi E-commerce Global disamping yang disebutkan oleh UndangUndang Perlindungan Konsumen adalah:
a. Membayar sesuai harga paket pemesanan atau pemebelian.
b. Mematuhi peraturan selama atau pada saat melakukan transaksi.
c. Kewajiban lain yang terdapat pada UUPK.

Berikut langkah - langkah pembelian produk di PT.Solusi E-commere Global (Mataharimall.com):

1. Silakan terlebih dahulu buat akun :
a. Buka Website Mataharimall.
compada toolbar google atau google
chrome lalu tampilan website terbuka, dibagian atas menu website klik tulisan belum terdaftar, setelah muncul drop down menu silakan pilih buat akun baru .

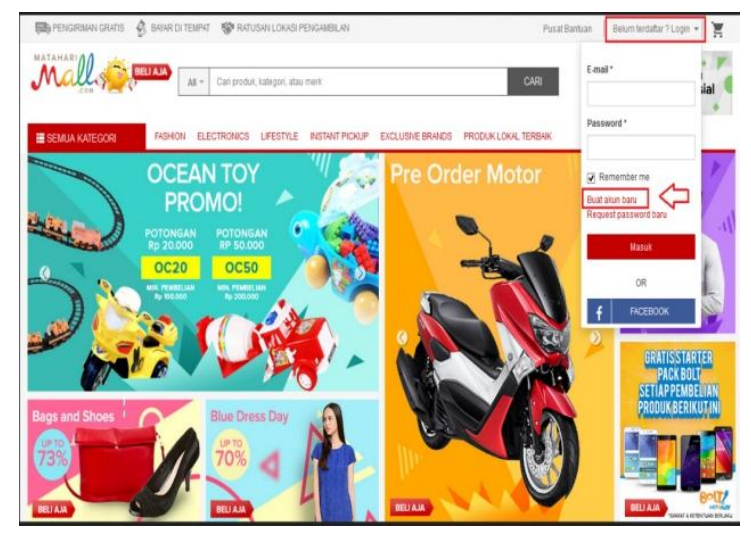

b. Di halaman form member baru, silahkan anda lengkapi data data berikut ini seperti data email, nama lengkap, jenis kelamin, tanggal lahir beserta password yang nantinya akan dipakai untuk login di MatahariMall.com. Jika data sudah lengkap dan benar klik persetujuan syarat dan ketentuan. Dan terakhir klik tombol Buat Akun Saya.

c.

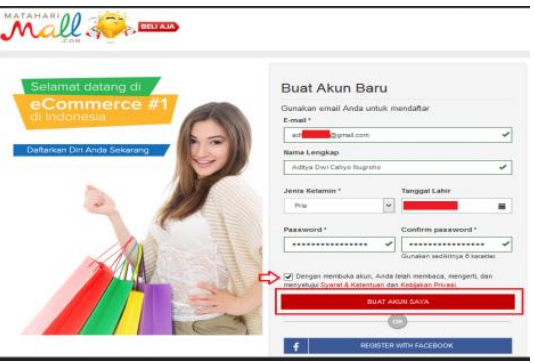

d. Jika anda diminta untuk konfirmasi alamat email, silahkan buka alamat email anda lalu klik tombol konfirmasi pada email yang dikirimkan oleh pihak Mataharimall.com, maka setelah itu anda telah bisa melakukan transaksi jual beli .

2. Bertransaksi melalui bayar ditempat/COD (Cash on Delivery).

Pembayaran ini memungkinkan anda untuk membayar langsung di kiosk kiosk Mataharimall.com, dengan metode pembayaran COD (Cash on Delivery) dengan menentukan produk yang mau dibeli di menu kategori, dengan produk - produk yang bertanda tertentu yakni di ujung kiri terdapat keterangan dengan tulisan penjual oleh Mataharimall.com,

Hypermant, Mataharistore.com,

Mataharimallelectronic, maupun produk - produk yang bekerjasama, dengan menentukan lokasi - lokasi kiosk yang terdapat di kota - kota tertentu.

3. Bertransaksi melalui Kartu Kredit .

Masuk ke website, Tentukan kategori dan pilih produk yang mau dibelik, lalu lakukan transaksi menggunakan kartu kredit.

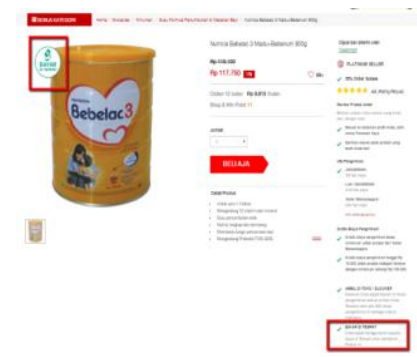




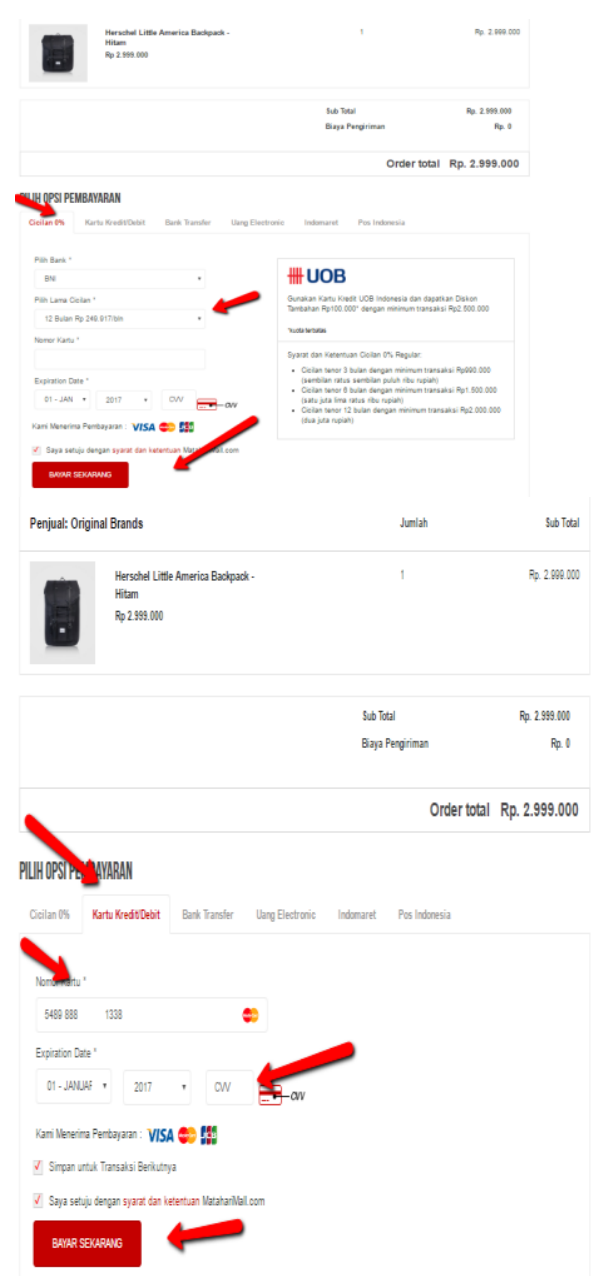

Pada saat pembayaran, mohon perhatikan detail data kartu kredit yang diperlukan, seperti 16 Digit nomor kartu kredit, masa berlaku kartu kredit dan CVV (3 angka dibagian belakang kartu), Jika data tidak sesuai/tidak valid maka dipastikan transaksi tidak bisa dilanjutkan. Metode pembayaran kart kredit, selain bisa full payment.

Anda juga bisa memilih pembayaran order menggunakan kartu kredit dengan cara di cicil (cicilan 0\%)

\section{Bank Transfer}

Anda dapat melakukan pembayaran melalui bank transfer dari bank manapun ke salah satu rekening MatahariMall.com dalam waktu 1x24 jam setelah pembelian. Jika Anda tidak melakukan pembayaran dalam 1x24 jam, pembelian akan dibatalkan secara otomatis.Setelah melakukan pembayaran Anda harus mengisi form konfirmasi pembayaran melalui link yang terdapat di e-mail konfirmasi pemesanan Andaatau di detail Pesanan Anda (Login --> Pesanan Saya --> Klik "detail order" yang ingin dikonfirmasi -> Klik "Konfirmasi Pembayaran").Form konfirmasi pembayaran wajib diisi secara lengkap dan akurat.

Tidak mengisi form konfirmasi pembayaran akan mengakibatkan keterlambatan dalam memproses pesanan Anda. Konfirmasi membutuhkan waktu 2x24 jam (hari kerja) setelah Anda melakukan konfirmasi via web. Untuk mempercepat proses verifikasi, lampirkan soft copy bukti pembayaran pada waktu mengisi form pembayaran. Status pembayaran akan berganti menjadi "pending shipment" saat pembayaran sudah berhasil diverifikasi oleh team kami, berikut langkah - langkah dalam melakukan transaksi virtual transfer :

a. Mandiri Virtual Transfer :

1. Pada menu utama, pilih transaksi lainya.

2. Pilih Trasnfer.

3. Pilih antar Bank Online.

4. Masukan jumlah tagihan yang akan dibayar secara lengkap (Pembayaran tidak sesuai otomatis akan ditolak)

5. Kosongkan No.referensi lalu tekan benar.

6. Pada halaman konfirmasi transfer akan muncul jumlah yang dibayarkan, nomor rekenening, dan nama merchant, jika informasi telah sesuai tekan benar.

b. BCA Virtual Transfer :

1. Pada menu utama, pilih transaksi lainya.

2. Pilih Trasnfer.

3. Pilih antar Bank Online

4. Masukan jumlah tagihan yang akan dibayar secara lengkap (Pembayaran tidak sesuai otomatis akan ditolak)

5. Kosongkan No.referensi lalu tekan benar. 
6. Pada halaman konfirmasi transfer akan muncul jumlah yang dibayarkan, nomor rekenening, dan nama merchant, jika informasi telah sesuai tekan benar.

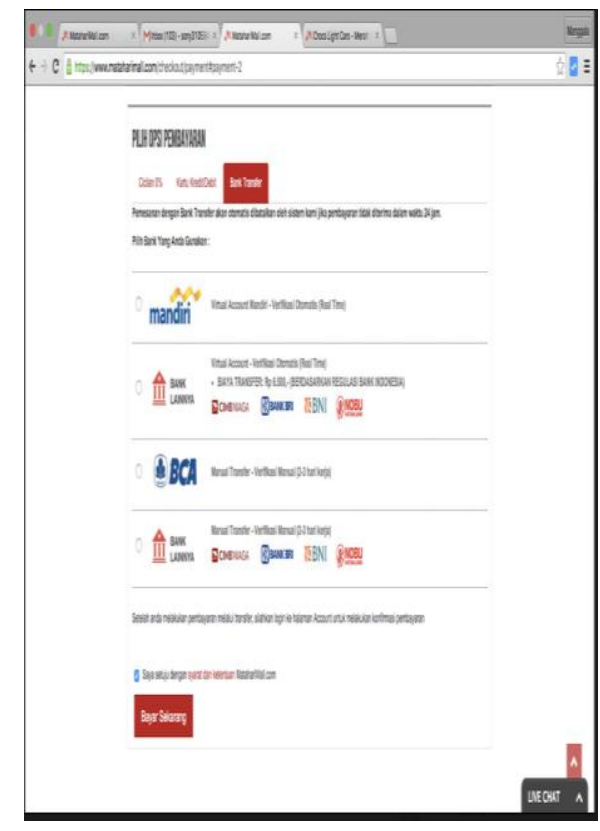

\section{Penyelesaian Sengketa Konsumen Pada Transaksi Elektronik (E-Commerce)Di PT. Solusi E-Commerce Global (Mataharimall.Com)}

Ketidak taatan pada isi transaksi konsumen, kewajiban, serta larangan sebagaimana diatur di dalam UndangUndang No. 8 Tahun 1999 tentang Perlindungan Konsumen dapat melahirkan sengketa antara pelaku usaha dan konsumen. Sengketa konsumen adalah sengketa yang berkenaan dengan pelanggaran hak-hak konsumen. Sengketa itu dapat berupa salah satu pihak tidak mendapatkan atau menikmati apa yang seharusnya menjadi haknya karena pihak lainnya tidak memenuhi kewajibannya, misalnya konsumen tidak mendapatkan pelayanan sesuai dengan yang disepakati, atau pelaku usaha tidak mendapatkan pembayaran yang sesuai dengan perjanjian.

Sebagaimana sengketa hukum pada umumnya, sengketa konsumen juga harus diselesaikan, sehingga tercipta hubungan baik antara pelaku usaha dan konsumen, dan masing-masing pihak mendapatkan kembali haknya sesuai kesepakatan. Penyelesaian sengketa dibidang hukum ini bertujuan memberi jalan keluar demi menjamin terpenuhinya hak-hak kedua belah pihak yang bersengketa guna terciptanya keadilan dan kepastian hukum sebagaimana mestinya.

Masalah penyelesaian sengketa konsumen pada transaksi elekktronik sama dengan penyelesaian sengketa konsumen pada umumnya, dalam Undang - Undang Perlindungan Konsumen diatur dalam Bab $\mathrm{X}$ yang terdiri dari empat pasal, yang dimulai dari Pasal 45 sampai Pasal 48. Pada Pasal 45 ayat (1) Undang-Undang No. 8 tahun 1999 tentang Perlindungan Konsumen (UUPK) dinyatakan bahwa: "Setiap konsumen yang dirugikan dapat menggugat pelaku usaha melalui lembaga yang bertugas menyelesaikan sengketa antara konsumen dan pelaku usaha atau peradilan yang berada di lingkungan peradilan umum".

Pasal 45 ayat 2 Undang-Undang Perlindungan Konsumen, penyelesaian sengketa konsumen dapat dilakukan melaui dua cara yaitu diselesaikan diluar pengadilan (non litigasi) dan diselesaikan melalui pengadilan (litigasi) yang dilakukan sesuai dengan pilihan sukarela para pihak yang bersengketa. Penyelesaian sengketa menurut ayat ini tidak menutup kemungkinan penyelesaian damai para pihak yang bersengketa. Pada setiap tahap diusahakan untuk menggunakan penyelesaian damai oleh kedua belah pihak yang bersengketa. Penyelesaian damai yang dimaksud adalah penyelesaian yang dilakukan oleh kedua belah pihak yang bersengketa (pelaku usaha dan konsumen) tanpa melalui pengadilan atau BPSK dan tidk bertentangan dngan undang-undang ini.

Undang-Undang No. 8 tahun 1999 membagi penyelesaian sengketa konsumen menjadi dua bagian, yaitu :

1. Penyelesaian Sengketa di Luar Pengadilan

a. Penyelesaian secara damai oleh para pihak

b. Penyelesaian melalui lembaga yang berwenang yaitu BPSK dengan menggunakan 
mekanisme konsisliasi, mediasi atau arbitrase.

2. Penyelesaian Sengketa Konsumen Melalui Proses Litigasi.

Dalam melaksanakan kegiatan perusahaan PT.Solusi E-commerce Global berusaha memberikan pelayanan yang terbaik kepada konsumen, hampir selama 2 tahun melaksanakan kegiatan usahanya, sejauh ini belum pernah ada sengketa konsumen yang dihadapi oleh PT.Solusi Ecommerce Global, namun tidak dipungkiri adanya komplain, komplain dari konsumen selama melakukan transaksi pembelian. Misalanya tentang kondisi barang, waktu tiba barang dan berbagai pelayanan lainnya, namun komplain-komplain tersebut sesegera mungkin untuk selesaikan secara damai.

Adapun permaslahan konsumen yang muncul dalam pelaksanaan kegiatan PT.Solusi E-commerce Global terhadap kepentingan konsumen adalah mengenai:

1. Barang rusak (Kondisi paket tidak layak).

2. Barang tidak berfungsi (Tidak dapat digunakan ).

3. Barang yang diterima tidak sesuai dengan depenelitian/foto (Beda tipe/ukuran/warna).

4. Barang bermasalah karena pengiriman (Salah kirim, pengiriman lebih dari batas waktu yang dijanjikan).

5. Barang tidak sesuai pesanan (Salah ukuran/tidak muat/salah warna).

6. Barang ada bagian yang hilang.

7. Berubah pikiran.

8. Barang sudah melewati masa kadaluuwarsa.

9. Tidak merasa memesan barang.

Terkait komplain-komplain yang diatas PT.Solusi E-commerce Global selaku pelaku usaha bertanggung jawab akan komplain konsumen tersebut, bentuk pertanggung jawabannya dengan cara Refund dan Tukar Barang Pengganti.

PT.Solusi E-commerce Global juga memiliki kebijakan dalam ketentuan ketentuan komplain - komplain yang dapat di pertanggung jawabkan dalam proses
Refund dan Tukar Barang Pengganti, diantaranya :

1. Produk dapat dikembalikan 14 hari kerja sejak tanggal penerimaan. Perhitungan dimulai dari tanggal anda menerima produk sampai tanggal cap pos yang tertera pada paket yang anda kembalikan kepada kami.

2. Pengembalian produk tidak berlaku untuk parfum, produk kecantikan, makanan, minuman, kontrasepsi, motor, mobil, atv, funitur besar, alat fitness, lingerie dan pakaian dalam, jam tangan, dan perhiasan.

3. Produk tidak boleh dalam keadaan rusak, kotor atau dicuci.

4. Jika anda menggunakan voucher pada saat pembelian, nilai voucher tidak dapat dikembalikan.

5. Untuk produk rusak, anda juga dapat menghubungi pihak garansi pabrik melalui kontrak yang tertera pada kartu garansi.

6. Berubah pikiran, untuk produk elektronik berlaku untuk 2 hari kerja, dan harus dalam keadaan rapid an tersegel.

Pasal 45 ayat (2) Undang-Undang Perlindungan Konsumen, penyelesaian sengketa konsumen dapat ditempuh melalui pengadilan (litigasi) atau diluar pengadilan (non litigasi). Pada PT.Solusi Ecommerce Global jika suatu saat terjadi sengketa konsumen maka penyelesaian dilakukan melalui secara damai ter oleh kedua belah pihak terlebih dahulu atau sering dikenal dengan istilah kekeluargaan namun jika dari upaya ini tidak memperoleh kesepakatan maka tidak menutup kemungkinan untuk penyelesaian sengketa dilakukan melalui upaya hukum lainnya baik jalur non litigasi maupunjalur litigasi sebagaimana disebutkan dalam Undang-Undang Perlindungan Konsumen.

\section{SIMPULAN}

Berdasarkan penelitian yang telah dilakukan pada bab-bab sebelumnya maka adapun yang menjadi kesimpulan penelitian ini adalah. 
1. Perlindungan Konsumen pada PT.Solusi E-commerce Global memiliki tanggung jawab secara kontaraktual dan perundang-undangan terhadap client-nya dan memberikan jaminan semua hak-hak konsumen sebagaimana yang ada dalam perjanjian yang telah mereka sepakati terlebih dahulu mulai, Sesuai Pasal 4 (empat) Undang-Undang No. 8 Tahun 1999 tentang Perlindungan Konsumen. Demi kepastian hukum bagi konsumen PT.Solusi E-commerce Global, telah mendapat mendapatkan pengesahaan dari Mentri Hukum dan Hak Azasi Manusia, dengan nomor AHU.5981.01.01.

2. Penyelesaian sengketa konsumen di Indonesia dapat dilakukan melalui Undang-Undang Perlindungan Konsumen Pasal 42 ayat (2) yaitu penyelesaian sengketa di luar pengadilan (nonlitigasi) dan penyelesaian sengketa melalui jalur pengadilan (litigasi),PT.Solusi Ecommerce Global belum pernah menhadapi sengketa konsumen namu hanya berupa kompalin-komplain dari kosumen (client) yang langsung diselesaikan saat itu juga.

\section{DAFTAR PUSTAKA}

\section{A. Buku}

Ahmad Miru, Prinsip-Prinsip Perlindungan Hukum Bagi Konsumen Di Indonesia, Jakarta: Rajagrafindo, 2013.

Andi Sunarto,SEI, Seluk Beluk E-commerce Penerbit Garailu, Jogjakarta,2009.

Amirudin dan Asikin Zainal., Pengantar Metode Penelitian Hukum, raja Grafindo Persada, Jakarta, 2006.

Dr.Siswanto Sunarso,SH,MH,M.kn, Hukum Infomasi \& Transaksi Elektronik,Studi Kasus Prita Mulyasari. Penerbit Rinek Cipta,2009.

Harianto, Dedi, Perlindungan Hukm Bagi Konsumen Terhadap Iklan
Menyesatkan, Ghalia

Indonesia,Bogor 2010.

Indrajit Ricardus Eko., E-commerce Kiat dan strategi di Dunia Maya, PT Efek Media Komutindo, Jakarta, 2001.

Kadir Muhammad Abdul., Hukum dan Penelitian Hukum., Citra Aditya Bakti, Bandung, 2004.

KristiyantiCelina Tri Siwi Hukum Perlindungan Konsumen, Sinar Grafika, Jakarta 2011.

Mamudji Sri, Metode Penelitian dan Penulisan Hukum, Badan Penerbit Fakultas Hukum Universitas Indonesia, Jakarta,2005.

Nasution Az., Hukum Perlindungan Konsumen,Jakarta Pusat,Diadit

Media,2002.

Siahaan N.H.T., Hukum Perlindungan Konsumen dan Tanggung Jawab Produk, Jakarta: Panterai 2005.

Soekanto Soerjono., Ringkasan Metdologi Penelitian Hukum Empiris, Indonesia Hilco, Jakarta, 1990.

Resa Raditio, SH, MH, Aspek Hukum Transaksi Elektronik (Perikatan, pembuktian, penyelesaian sengketa J,Yogyakarta;Graha Ilmu,2014.

Zein Yahya Ahmad,SH,MH., Kontrak Elektronik \& Penyelesaian Sengketa Bisnis E-commerce,CV.Mandar Maju,Tarakan 2009

\section{B. Peraturan Perundang-undangan}

Kitab Undang - Undang Hukum Perdata.

Kitab Undang - Undang Hukum Pidana.

Undang - Undang Nomor 8 Tahun 1999 Tentang Perlindungan Konsumen.

Undang - Undang Nomor 19 Tahun 2016 Tentang Infomasi dan Transaksi elektronik.

Surat Keputusan Menteri Perindustrian Dan Perdagangan (Menperindag) No. 350/Mpp/Kep/12/2001 


\section{Jurnal}

NY Simbolon, Tinjauan Yuridis Terhadap

Tindak Pidana Pencemaran

Nama Baik Melalui Media Massa

Dalam Perspektif Hukum Pidana, Jurnal Ilmiah Simantek, Vol. 1 No.3 september 2017, http://sciencemakarioz.org/jurnal /index.php/SIMANTEK/article/vie $\mathrm{w} / 133$

\section{Internet}

http://www.duniacyber.com/interactives/i nternet basic.php .

Evi Retnowulan, Jurnal Ilmu Hukum ,"Tinjauan Hukum Jual Beli Secara Online", $\quad$ www.jurnalilmuhukum.com.

https://id.wikipedia.org/wiki/Yayasan Le mbaga Konsumen Indonesia. http://www.patartambunan.com/ pengertian-e-commerce-manfaatserta-keuntungan-ecommerce/Diakses.

http://siswaspk.kemendag.go.id/berita $\not 121$. 